\title{
The effect of artificial tear administration on visual field testing in patients with glaucoma and dry eye
}

Department of

Ophthalmology,

Marmara University School of Medicine, Kosuyolu İstanbul, Turkey

Correspondence: Ö Yenice, Atif bey sok. Yeniköy sites: $A 13 / 2$

Acibadem, Istanbul, Turkey

Tel/Fax: + 902163279538

E-mail: yeniceozlem@

yahoo.com

Received: 11 July 2005 Accepted in revised form: 29 November 2005;

Published online:

27 January 2006
Abstract

Aim To examine the effects of artificial tear administration on perimetry of primary open-angle glaucoma patients with dry eye.

Methods A total of 40 patients with primary open-angle glaucoma experienced in automated perimetry with symptoms of dry eye were enrolled in this study. After their pretest visit, they were instructed to use artificial tear four times a day in both eyes for 1 week. After 1 week, patients had visual field testing. Test taking time, reliability parameters (false-positive and false-negative errors) visual field indices and number of depressed points at different probability levels $(P<5 \%, P<2 \%, P<1 \%, P<0.5 \%)$ in both total and pattern deviation plots were compared using paired $T$ test.

Results We found significant improvement in reliability parameters (false-positive errors from $2.4 \pm 2.1$ to $2.1 \pm 1.9, P=0.02$; and false-negative errors from $7.3 \pm 6.4$ to $4.8 \pm 3.6$, $P=0.01$ ) and visual field indices (MD increased from $5.97 \pm 5.61$ to $4.57 \pm 4.53$, $P=0.001$; PSD from $4.67 \pm 2.95$ to $4.13 \pm 2.77$, $P=0.04$ and SF decreased from $2.24 \pm 1.23$ to $1.83 \pm 0.77, P=0.04)$ in the second testing after artificial tear administration. Test time significantly increased from $11.66 \pm 2.55 \mathrm{~min}$ to $14.26 \pm 1.36, P=0.001$. The number of depressed points at probability levels $P<1 \%$ $(P=0.03)$ and $P<0.5 \%(P=0.04)$ at total deviation plot and $P<2 \%(P=0.02)$ and $P<0.5 \%(P=0.009)$ in pattern deviation plot decreased significantly. Conclusion Artificial tear administration in glaucomatous patients with dry eye seems to
Ö Yenice, A Temel and Ö Örüm

improve significantly reliability parameters and visual field indices.

Eye (2007) 21, 214-217. doi:10.1038/sj.eye.6702252; published online 27 January 2006

Keywords: glaucoma; visual field; dry eye; artificial tears

\section{Introduction}

Automated perimetry is a standard procedure in the management of glaucoma and is widely used to determine functional loss. Perimetry is a standard procedure to determine whether glaucomatous damage is worsening. However, the value of automated perimetry testing results depends on the reliability of the patient's response and it has significant intertest and intratest variability. Thus, differentiation of true progression from the inherent fluctuation in the threshold estimate between any two consecutive visual field examinations is still a major clinical dilemma. The outcome of any given single visual field examination can be influenced by many factors including pupil size $^{1}$ refractive error, ${ }^{2}$ media opacities, ${ }^{3}$ learning, ${ }^{4,5}$ fatigue ${ }^{6,7}$ medical therapy, ${ }^{8}$ and random variations in the physiological status ${ }^{9}$ of the patient.

Dry eye and ocular surface impairment are most common and important side effects of antiglaucoma drugs which may cause ophthalmologist to alter the medication. ${ }^{10,11}$ In addition to this, toxic and inflammatory effects of antiglaucoma drugs on ocular surface may cause variations of visual acuity and the occurrence of pseudoscotoma seen on perimetry. ${ }^{12}$ Any disturbance of precorneal tear 
film may cause deterioration in visual quality, as cornea and precorneal tear film are the most important optic media of the eye. Reports presented in the literature that show improvement of contrast sensitivity, ${ }^{13}$ corneal topography ${ }^{14}$ and mean thresholds in automated perimetry ${ }^{12}$ in patients with dry eye after artificial tear administration. There is also one study which studies the tear substitute effect on 10-2 central visual field testing but there is no study which evaluates the effect of a tear substitute on 30-2 program, which is commonly used in patients with glaucoma, on subjects having both glaucoma and dry eye.

\section{Methods}

Patients with diagnosis of primary open-angle glaucoma and dry eye treated with topical antiglaucamatous eye drops who have long-term follow-up with at least four or more standard visual fields, best-corrected visual acuity of $20 / 40$ or better, spherical refraction within \pm 5.0 diopters (D) and a cylinder correction within $\pm 2.0 \mathrm{D}$ were included in this study. Any history of ocular trauma, intraocular surgery or refractive corneal procedures was ground for exclusion. None of the involved patient had concurrent use of artificial tears during the study.

The diagnosis of dry eye was made on the basis of presence of symptoms of dry eye (feeling of burning, dryness, and foreign body sensation in the eye), Schirmer I test results less than $10 \mathrm{~mm}$ without anaesthesia or less than $5 \mathrm{~mm}$ with topical $0.5 \%$ proparacaine hydrochloride anaesthesia and tear film break-up time (TBUT) of less than $10 \mathrm{~s}$.

After receiving written informed consent, all patients underwent visual field testing. Standard visual field testing was performed on the Humphery Field Analyzer (Zeiss Humphrey Sysyems) by a trained technician using standard full threshold strategy with program 30-2 and size III white stimulus on a white background (31.5 apostilbs). To be considered reliable, a test had to have false-positive and false-negative responses and fixation losses $<20 \%$. Patients were then given artificial tear solution to use (Tears Naturale II, Alcon Laboratories Inc.) four times a day for 1 week and called for control visual field testing.

At the second visit, one drop of artificial tear was instilled into the inferior conjunctival sac of each patient. Patients were instructed to blink several times. At $1 \mathrm{~min}$ after the intervention, visual field testing was performed again as previously described. The reliability parameters (false-positive and false-negative errors), visual field indices (MD, PSD, SF, and CPSD), number of depressed points at probability levels $(P<5 \%, P<2 \%, P<1 \%$, and $P<0.5 \%)$ of total and pattern deviation plots and test time were obtained from the results of each test session for each patient. The parameters obtained from visual field testing before and after artificial tear administration were compared using paired $T$-test. $P$-values $<0.05$ were considered statistically significant.

\section{Results}

All patients completed the study protocol, and only available data and reliable visual fields were used in this study. The age of patients ranged between 46 and 84 years (mean $65.8 \pm 10.6$ years). The patients had been treated with antiglaucomatous eye drops for a median of 2.4 years (range 1-11 years). Of these 40 patients, 26 had received two or more antiglaucoma drugs for at least 1 year (mean $5.2 \pm 4.8$ years; range $1-11$ years). All others were using mono-therapy. The mean Schirmer I,

Schirmer with local anaesthesia and TBUT test results were $5.9 \pm 2.5 \mathrm{~mm}, 2.6 \pm 1.6 \mathrm{~mm}$, and $8.3 \pm 1.6 \mathrm{~s}$, respectively.

The visual field indices of first and second visual field testing and test time before and after artificial tear administration are shown in Table 1.

Statistically significant improvement in false-negative errors $(P=0.01)$, false-positive $(P=0.02)$ errors, MD's $(P=0.001)$, PSD's $(P=0.04)$, and SF's $(P=0.04)$ were observed after artificial tear administration. There was not any statistically significant change in CPSD $(P=0.56)$ and the test time was significantly increased $(P=0.001)$ after the artificial tear replacement.

Change in the number of depressed points at different probability levels in total deviation plot before and after artificial tear replacement is shown in Table 2. The number of depressed points at probability level $<1 \%$ $(P=0.03)$ and $<0.5 \%(P=0.04)$ in total deviation plot were significantly decreased.

Table 1 Test time, reliability indices, mean deviation (MD), pattern standard deviation (PSD) of visual fields before and after artificial tear administration

\begin{tabular}{lccc}
\hline Effect of tear application on visual field parameters \\
\hline & $\begin{array}{c}\text { Before tear } \\
\text { application }\end{array}$ & $\begin{array}{c}\text { After tear } \\
\text { application }\end{array}$ & P-value \\
\hline Test time (min) & $11.66 \pm 2.55$ & $14.26 \pm 1.36$ & $0.001^{*}$ \\
FN (\%) & $7.3 \pm 6.4$ & $4.8 \pm 3.6$ & $0.01^{*}$ \\
FP (\%) & $2.4 \pm 2.1$ & $2.1 \pm 1.9$ & $0.02^{*}$ \\
Fixation losses (\%) & $10.3 \pm 8.2$ & $9.4 \pm 8.6$ & $0.01^{*}$ \\
MD & $5.97 \pm 5.61$ & $4.57 \pm 4.53$ & 0.001 \\
PSD & $4.67 \pm 2.95$ & $4.13 \pm 2.77$ & $0.04^{*}$ \\
SF & $2.24 \pm 1.23$ & $1.83 \pm 0.77$ & $0.04^{*}$ \\
CPSD & $3.66 \pm 2.95$ & $3.49 \pm 2.81$ & 0.56 \\
\hline
\end{tabular}

*Statistically significant difference $(P<0.05)$. 
Table 2 Number of significantly depressed points on total deviation probability map before and after artificial tear administration

\begin{tabular}{lccl}
\hline Effect of tear application on total deviation probability map \\
\hline $\begin{array}{c}\text { Before tear } \\
\text { application (n) }\end{array}$ & $\begin{array}{c}\text { After tear } \\
\text { application (n) }\end{array}$ & P-value \\
\hline$P<5 \%$ & $8.30 \pm 5.72$ & $8.33 \pm 5.73$ & 0.9 \\
$P<2 \%$ & $4.20 \pm 3.23$ & $5.0 \pm 4.85$ & 0.2 \\
$P<1 \%$ & $4.58 \pm 3.79$ & $3.15 \pm 3.11$ & $0.03^{*}$ \\
$P<0.5 \%$ & $12.74 \pm 10.81$ & $7.38 \pm 5.56$ & $0.005^{*}$ \\
\hline
\end{tabular}

*Statistically significant difference $(P<0.05)$.

Table 3 Number of significantly depressed points on pattern deviation probability map before and after artificial tear administration

\begin{tabular}{lccl}
\hline Effect of tear application on pattern deviation probability map \\
\hline & $\begin{array}{c}\text { Before tear application } \\
\text { (n) }\end{array}$ & $\begin{array}{c}\text { After tear application } \\
\text { (n) }\end{array}$ & P-value \\
\hline$P<5 \%$ & $4.94 \pm 3.91$ & $5.02 \pm 4.34$ & 0.9 \\
$P<2 \%$ & $3.79 \pm 3.31$ & $2.56 \pm 2.21$ & $0.02^{*}$ \\
$P<1 \%$ & $3.07 \pm 3.41$ & $2.23 \pm 2.24$ & 0.1 \\
$P<0.5 \%$ & $7.94 \pm 7.18$ & $5.48 \pm 5.82$ & $0.009^{*}$ \\
\hline
\end{tabular}

*Statistically significant difference $(P<0.05)$.

Change in the number of the depressed points at different probability levels in pattern deviation curve before and after artificial tear replacement is shown in Table 3 . The number of depressed points at probability level $<2 \%(P=0.02)$ and $<0.5 \%(P=0.009)$ were significantly decreased in pattern deviation plot.

\section{Discussion}

Symptoms and signs of dry eye are common among the elderly population. ${ }^{15}$ Studies showed a clear lack of correlation between presence of dry eye symptoms and diagnostic tests. ${ }^{15,16}$ They suggested the diagnosis of dry eye can solely be made with presence of dry eye symptoms. ${ }^{15,16}$ Our glaucoma patients had dry eye symptoms and these were confirmed with diagnostic tests.

Long-term use of antiglaucoma drugs have been associated with toxic as well as inflammatory changes of the ocular surface. ${ }^{17,18}$ Almost half of the patients experience symptoms of ocular irritation with their glaucoma medication. Side effects of antiglaucomatous drugs are real healthcare concern which decreases the compliance of patients to treatment. They cause conjunctival hyperaemia, conjunctivitis, blepharitis, periorbital dermatitis, superficial punctate keratitis, pseudopemfigoid, contact allergy, and dry eye. ${ }^{17-21}$ These drugs also decrease the stability of the precorneal tear film and worsen the pre-existing dry eye symptoms. ${ }^{19}$ Ocular surface side effects of antiglaucomatous drugs are caused by either the drug itself or by preservatives. ${ }^{21}$ Especially preservatives of antiglaucomatous drugs decrease tear production and goblet cell density. ${ }^{17-21}$ Additionally, corneal and conjunctival sensitivity diminish which resulted in a decreased blink rate and tear turnover. ${ }^{19}$ Moreover, preservatives have detergent effect on the precorneal lipid layer resulting in decreased corneal tear film stability and increased evaporation. ${ }^{21}$ Dry eye which is one of the most common complication of antiglaucomatous drugs occur as a result of all these undesired effects. Cornea has a high refractive power of $49 \mathrm{D}$ which makes it the highest refractive optical interface in the human eye. For optimal quality, the corneal surface needs homogeneous wetting. This wetting is provided by the tear film which is the 'polish' of the cornea. ${ }^{12}$ Thus, any disturbance in tear film quality may result in poor visual quality and discomfort leading to erroneous visual tasks like visual field.

At present the data in literature shows improvement in contrast sensitivity ${ }^{13}$ and corneal topography ${ }^{14}$ in patients with dry eye after artificial tear administration. There is only one study which evaluates the effect of a tear substitute on visual field and it shows improvement of thresholds in automated perimetry. ${ }^{12}$ This study was performed on central 10-2 visual field and there was a significant improvement in macular thresholds $($ mean $+11.75 \mathrm{~dB})$.

After artificial tear administration we observed statistically significant improvement in many of the visual field parameters including mean thresholds, number of depressed points in probability maps as well as reliability indices. We found significant improvement in reliability parameters (false-positive errors from $2.4 \pm 2.1$ to $2.1 \pm 1.9$ and false-negative errors from $7.3 \pm 6.4$ to $4.8 \pm 3.6$ ) and visual field indices of first MD increased from $5.97 \pm 5.61 \mathrm{~dB}$ to $4.57 \pm 4.53$, PSD from $4.67 \pm 2.95$ to $4.13 \pm 2.77$, and SF decreased from $2.24 \pm 1.23$ to $1.83 \pm 0.77$ in the second visual field testing after artificial tear administration. Test time increased significantly from $11.66 \pm 2.55 \mathrm{~min}$ to $14.26 \pm 1.36$ $(P=0.001)$ which was approximately $22 \%$. We think this increase was due to the more reliable testing and better concentration achieved after artificial tear application.

Additionally, the number of depressed points at probability levels $P<1 \%$ and $P<0.5 \%$ at total deviation plot and $P<2 \%$ and $P<0.5 \%$ in pattern deviation plot decreased significantly. The decrease observed at lower probability levels may be also explained by better concentration which affects the threshold value. 
The improvements observed in visual field testing cannot be due to learning effect of recurrent test sessions as our study group was composed of glaucoma patients who were experienced subjects. Studies examining learning effects in visual field tests showed that the most significant difference was observed between the first and second perimetry sessions. ${ }^{22,23}$ In our study, patient had already at least four visual field testings before.

Visual field testing requires concentration. This concentration during examination cause fewer blinks resulting decrease in tear film stability. Additionally, topical antiglaucamatous drugs had been shown to decrease corneal and conjunctival sensitivity which diminishes blink rate and tear turnover. ${ }^{19}$ All these effects might cause the thresholds appear worse than they actually are which shows improvement after a tear substitute.

In conclusion, primary open-angle glaucoma patients with symptoms of dry eye, who are elderly and use antiglaucamatous eye drops may be given artificial tears before visual field examination to avoid any improper confirmation of visual field progression.

\section{References}

1 Lindenmuth KA, Skuta GL, Rabbani R, Musch DC, Bergstrom TJ. Effects of pupillary constriction on automated perimetry in normal eyes. Ophthalmol 1989; 96: 1298-1301.

2 Weinreb RN, Perlman JP. The effect of refractive correction on automated perimetric thresholds. Am J Ophthalmol 1986; 101: 706-709.

3 Guthauser U, Flammer J. Quantifying visual field damage caused by cataract. Am J Ophthalmol 1988; 106: 480-484.

4 Heijl A, Lindgreen G, Olsson J. The effect of perimetric experience in normal subjects. Arch Ophthalmol 1989; 107: 81-86.

5 Wild JM, Dengler-Harles M, Searle AE. The influence of the learning effect on automated perimetry in patients with suspected glaucoma. Acta Ophthalmol Scand 1989; 67: 537-545.

6 Hudson C, Wild JM, O'Neil EC. Fatique effects during a single session of automated static threshold perimetry. Invest Ophthalmol Vis Sci 1994; 35: 268-280.

7 Heijl A, Drance SM. Changes in differential threshold in patients with glaucoma during prolonged perimetry. $\mathrm{Br} J$ Ophthalmol 1983; 67: 512-516.
8 Haas A, Flammer J. Influence of diazepam on differential light sensitivity. Doc Ophthalmol Proc Ser 1985; 42: 527-532.

9 Flammer J, Drance SM, Schulzer M. The estimation and testing of the components of long-term fluctuation of the differential light thresholds. Doc Ophthalmol Proc Ser 1983; 35: 383-389.

10 Pisella PJ, Pouliquen P, Baudouin C. Prevalence of ocular symptoms and signs with preserved and preservative free glaucoma medication. Br J Ophthalmol 2002; 86: 418-423.

11 Yalvaç IS, Gedikodlu G, Yaragöz Y, Akgun U, Nurozler A, Koc $\mathrm{F}$ et al. Effects of antiglaucoma drugs on ocular surface. Acta Ophthalmol Scand 1995; 73: 246-248.

12 Rieger G. The importance of precorneal tear film for the quality of optical imaging. Br J Ophthalmol 1992; 76: 157-158.

13 Huan FC, Tseng SH, Shih MS. Effect of artificial tears on corneal surface regularity, contrast sensitivity and glare disability in dry eyes. Ophthalmology 2002; 104: 1934-1940.

14 Pavlopoulos GP, Horn J, Feldman ST. The effect of artificial tears on computer assisted corneal topography in normal eyes and after penetrating keratoplasty. Am J Ophthalmol 1995; 119: 712-722.

15 Schein OD, Munoz B, Tielsch JM. Prevalence of dry eye among the elderly. Am J Ophthalmol 1997; 124: 723-728.

16 Schein OD, Munoz B, Tielsch JM. Relation between sign and symptoms of dry eye in the elderly. Ophthalmology 1997; 104: 1395-1401.

17 Herreras JM, Pastor JC, Calonge M, Asensio VM. Ocular surface alteration after long-term treatment with an antiglaucomatous drug. Ophthalmology 1992; 99: 1082-1088.

18 Van Beek LM, Keizer RJ, Polak BC, Elzenaar PR, van Haeringen NJ, Kijlstra A. Incidence of ocular side effects of topical $\beta$ blockers in the Netherlands. Br J Ophthalmol 2000; 84: 856-859.

19 Burstein NL. The effects of topical drugs and preservatives on the tears and corneal epithelium in dry eye. Trans Ophthalmol Soc UK 1985; 104: 402-409.

20 Brandt JD, Wittpen JR, Katz LJ, Steinmann WN Conjunctival impression cytology in patients with glaucoma using long-term topical medication. Am J Ophthalmol 1991; 112: 297-301.

21 De Saint Jean M, Debbasch C, Brignole F, Rat P, Warnet JM, Baudouin C. Toxicity of preserved and unpreserved antiglaucoma topical drugs in an in vitro model of conjunctival cells. Curr Eye Res 2000; 20: 85-94.

22 Heijl A, Bengtsson B. The effect of perimetric experience in patients with glaucoma. Arch Ophthalmol 1996; 114: 19-22.

23 Horani A, Frenkel S, Yahalom C. The learning effect in visual field testing of healthy subjects using frequency doubling technology. J Glaucoma 2002; 11: 511-516. 